UNIVERSIDADE DE SÃO PAULO

FACULDADE DE ODONTOLOGIA DE RIBEIRÃO PRETO

DINAH RIBEIRO AMORAS

EFEITO DE BEBIDAS NO ESMALTE DENTAL SUBMETIDO A DESAFIO EROSIVO COM ÁCIDO CLORÍDRICO

RIBEIRÃO PRETO

2010 


\section{EFEITO DE BEBIDAS NO ESMALTE DENTAL SUBMETIDO A DESAFIO EROSIVO COM ÁCIDO CLORÍDRICO}

Dissertação apresentada à Faculdade de Odontologia de Ribeirão Preto da Universidade de São Paulo para obtenção do título de Mestre em Odontologia Restauradora

Área de Concentração: Dentística

Orientadora: Profa. Dra. Mônica Campos Serra

Ribeirão Preto

2010 
Autorizo a reprodução e divulgação total ou parcial deste trabalho, por qualquer meio convencional ou eletrônico, para fins de estudo e pesquisa, desde que citada a fonte.

Catalogação da Publicação

Serviço de Documentação Odontológica

Faculdade de Odontologia da Universidade de São Paulo

FICHA CATALOGRÁFICA

Amoras, Dinah Ribeiro

Efeito de bebidas no esmalte dental submetido a desafio erosivo com ácido cloridrico. Ribeirão Preto, 2010.

51 p. il.; $30 \mathrm{~cm}$

Dissertação de Mestrado, apresentada à Faculdade de Odontologia de Ribeirão Preto/USP. Área de concentração: Dentística.

Orientadora: Serra, Mônica Campos.

1. Esmalte. 2. Erosão dentária. 3. Ácido clorídrico. 4. In vitro 
Nome: AMORAS, Dinah Ribeiro

Título: Efeito de bebidas no esmalte dental submetido a desafio erosivo com ácido clorídrico

Dissertação apresentada à Faculdade de Odontologia de Ribeirão Preto da Universidade de São Paulo para obtenção do título de Mestre em Odontologia Restauradora.

Área de concentração: Dentística

Aprovado em:

\section{Banca Examinadora}

Prof. Dr. Instituição

Julgamento: Assinatura:

Prof. Dr. Instituição

Julgamento: Assinatura:

Prof. Dr. Instituição

Julgamento: Assinatura: 
DEDICATÓRIA 
DEDICO ESTE TRABALHO...

Aos meus pais Dinair e Romeu Amoras (in memorian), por todo amor e incentivo que me dedicaram o que foi fundamental na minha formação como pessoa.

Ao meu irmão Wladimir Amoras (in memorian), pelos bons momentos vividos.

Ao meu irmão Romeu Amoras, pelo carinho e apoio.

"Nem sempre temos a exata noção da "sinfonia da vida", da qual participamos. Ela é muito maior do que podemos imaginar, e precisamos contribuir com nosso acorde para que a melodia se complete".

Hammed 
AGRADECIMENTOS ESPECIAIS 


\section{AGRADECIMENTOS ESPECIAIS}

A Deus, "Inteligência suprema, causa primeira de todas as coisas", por iluminar meus caminhos com seu amor e misericórdia infinitos.

À Profa. Dra. Mônica Campos Serra, por sua disposição em compartilhar conhecimentos. Agradeço por sua orientação segura, precisa e muito atenciosa.

À Profa. Dra. Silmara Aparecida Milori Corona, por toda atenção e carinho com que sempre me atendeu. Pela confiança e apoio.

Ao Prof. Dr. Antonio Luiz Rodrigues Júnior, pela inestimável contribuição para realização deste trabalho.

"Não basta ensinar ao homem uma especialidade.

É necessário que adquira um sentimento, um senso prático daquilo que vale a pena ser empreendido, daquilo que é belo, do que é moralmente correto". 
AGRADECIMENTOS 


\section{AGRADECIMENTOS}

À Faculdade de Odontologia de Ribeirão Preto - USP, representada pelo Digníssimo Diretor Prof. Dr. Osvaldo Luiz Bezzon e pelo Vice-Diretor Prof. Dr. Valdemar Malet da Rocha Barros.

À coordenação geral da Pós-Graduação da Faculdade de Odontologia de Ribeirão Preto - USP, na pessoa da Profa. Dra. Léa Assed Bezerra da Silva.

À coordenação do curso de Pós-Graduação em Odontologia Restauradora, da Faculdade de Odontologia de Ribeirão Preto - USP, na pessoa do Prof. Dr. Manoel Damião de Sousa Neto.

Aos Professores do Departamento de Odontologia Restauradora da Faculdade de Odontologia de Ribeirão Preto.

Às Profa. Dra. Izabel Cristina Fröner e Profa. Dra. Telma Nunes do Nascimento, pelo carinho e por contribuírem para que estes anos fossem agradáveis momentos de convivência.

À Anna Maria e Giuliana Toledo, amigas sempre presentes compartilhando os momentos difíceis e as alegrias da minha vida.

Ao Antonio Xavier, querido amigo a quem agradeço por sempre me ouvir quando preciso, ponderar e me incentivar a seguir em busca de meus ideais.

Aos amigos da CDA, Anna, Edson, Mariza e Odilon, porque é muito bom conviver com vocês.

À Odete Dias, que me acolheu em Ribeirão Preto e em sua amizade.

À Paula Fieschi, por sua generosa e inestimável ajuda com a parte gráfica deste trabalho.

Aos colegas da Pós-Graduação, pelos bons momentos de convivência durante estes anos. 
À Ana Cristina Polizello, técnica do Laboratório de Bioquímica da Faculdade de Ciências Farmacêuticas de Ribeirão Preto-USP, pela magnânima colaboração na dosagem de flúor do experimento.

À Patrícia Marchi, técnica do laboratório de Dentística da Faculdade de Odontologia de Ribeirão Preto-USP, por sua atenção e auxílio durante os experimentos.

Ao Carlos Feitosa, secretário da Pós-Graduação do departamento de Odontologia Restauradora da Faculdade de Odontologia de Ribeirão Preto - USP, pelo seu trabalho competente e solicitude.

Aos funcionários do Departamento de Odontologia Restauradora da Faculdade de Odontologia de Ribeirão Preto - USP.

Aos funcionários da Seção de Pós-Graduação da Faculdade de Odontologia de Ribeirão Preto - USP.

Aos demais funcionários da FORP-USP, pois cada um, à sua maneira, contribuiu para o bom andamento do curso de mestrado.

A CAPES (Coordenação de Aperfeiçoamento de Pessoal de Nível Superior), pela concessão da bolsa de estudo.

Ao CNPq (Conselho Nacional de Desenvolvimento Científico e Tecnológico), pelo apoio através dos processos: 309219/2009-4 e 504504/2010-0.

A todos que, direta ou indiretamente, contribuíram para que esse trabalho fosse concluído. 
A vida está cheia de desafios que, se aproveitados de forma criativa, transformam-se em oportunidades". 


\title{
RESUMO
}

\begin{abstract}
AMORAS, D. R. EFEITO DE BEBIDAS NO ESMALTE DENTAL SUBMETIDO A DESAFIO EROSIVO COM ÁCIDO CLORÍDRICO. 2010. 51 p. Dissertação de Mestrado - Faculdade de Odontologia de Ribeirão Preto, Universidade de São Paulo, Ribeirão Preto, 2010.
\end{abstract}

A erosão dental de origem endógena apresenta alta prevalência e o efeito da ingestão frequente de determinadas bebidas poderia intensificar ou atenuar a lesão no esmalte. A análise do potencial erosivo das bebidas é uma estratégia importante para prevenir seu efeito na estrutura dental. Neste contexto, este estudo avaliou através de um modelo in vitro o efeito de bebidas no esmalte dental previamente submetido a desafio erosivo com ácido clorídrico. O fator em estudo foi o tipo de bebida, em cinco níveis: refrigerante de limão de baixa caloria (Sprite Zero CocaCola® Brasil), leite Ultra Higt Temperature integral (Parmalat $\left.{ }^{\circledR}\right)$, extrato de soja integral (Ades $\AA$ Original), chá preto pronto para beber de baixa caloria sabor pêssego (Leão Ice Tea Zero Coca-Cola ${ }^{\circledR}$ Brasil) e água mineral natural (Prata®). 75 espécimes de esmalte bovino foram distribuídos entre os 5 tipos de bebida $(n=15)$, de acordo com delineamento em blocos completos e casualizados. Para a formação das lesões de desgaste erosivo, os espécimes foram imersos por 2 minutos em 10 $\mathrm{ml}$ de solução aquosa de ácido clorídrico 0,01 M. Posteriormente foram lavados com água deionizada, imersos em saliva artificial a $37^{\circ} \mathrm{C}$ por 2 horas. Foram feitas imersões em $20 \mathrm{ml}$ das bebidas por 1 minuto, 2 vezes ao dia por 2 dias, sob temperatura ambiente. Nos intervalos entre as imersões os espécimes permaneceram em saliva artificial a $37^{\circ} \mathrm{C}$. A variável de resposta utilizada foi a microdureza superficial do esmalte. ANOVA e o teste de Tukey demonstraram diferenças altamente significativas $(p<0,00001)$ no esmalte exposto ao ácido clorídrico e às bebidas. O refrigerante de limão provocou uma diminuição da microdureza superficial significativamente maior do que as demais bebidas. O chá preto de baixa caloria provocou diminuição da microdureza significativamente maior 
que a água mineral, o leite UHT e o extrato de soja, porém menor que o refrigerante à base de limão. Leite UHT, extrato de soja e água mineral não proporcionaram diminuição adicional na microdureza do esmalte previamente erodido. Dentre as bebidas analisadas, o refrigerante de limão com baixa caloria e o chá preto pronto para beber com baixa caloria potencializaram a erosão do esmalte dental.

PALAVRAS CHAVE: Esmalte. Erosão dentária. Ácido clorídrico. In vitro. 


\title{
ABSTRACT
}

\begin{abstract}
AMORAS, D. R. EFFECT OF BEVERAGES ON DENTAL ENAMEL SUBMITTED TO EROSIVE CHALLENGE WITH HIDROCHLORIC ACID. 2010. 51 p. Dissertação de Mestrado - Faculdade de Odontologia de Ribeirão Preto, Universidade de São Paulo, Ribeirão Preto, 2010.
\end{abstract}

The erosive tooth wear of endogenous origin can be enhanced by frequent consumption of acidic beverages, worsening the damage to the enamel. Analysis of the erosive potential of beverages is a strategy to prevent dental erosion. In this context, this study evaluated through an in vitro model the effect of beverages on dental enamel previously subjected to erosive challenge with hydrochloric acid. The factor under study was the type of beverage, in five levels: soda lime, low calorie Sprite Zero Coca-Cola ${ }^{\circledR B}$ Brasil (positive control), Ultra Higt Temperature milk Parmalat $\Theta$, soymilk Ades $\AA$ Original, black tea ready to drink low calorie pec Leão Ice Tea Zero Coca-Cola ${ }^{\circledR B}$ Brasil, Prata $\AA$ natural mineral water (negative control). 75 bovine enamel specimens were distributed among the five types of beverages $(n=$ 15), according to randomized complete block design. The response variable was quantitative enamel microhardness. The 75 specimens were immersed in $10 \mathrm{ml}$ aqueous solution of hydrochloric acid $0.01 \mathrm{M}$ for 2 minutes. Later were washed with deionized water, immersed in artificial saliva at $37^{\circ} \mathrm{C}$ for 2 hours at the end of this period evaluated the surface microhardness $(\mathrm{KHN})$. The specimens were randomly divided into 5 groups, underwent three experimental and two control treatments. made 2 immersed daily, $20 \mathrm{ml}$ for 1 minute at room temperature for 2 days. In between dips specimens kept in $20 \mathrm{ml}$ artificial saliva at $37^{\circ} \mathrm{C}$. ANOVA and Tukey's test showed highly significant differences $(p<0.00001)$ in the enamel exposed to hydrochloric acid and beverages. The soda lemon soft drink caused a decrease in microhardness significantly higher than other beverages. The low calorie black tea ready to drink caused a reduction in microhardness significantly higher than the mineral water, UHT milk and soymilk, but smaller than the soda lemon soft drink, 
UHT milk, soymilk and mineral water provided no further decrease in previously eroded enamel microhardness. The low calorie soft drink lemon soda and low calorie black tea ready to drink have worsened the erosion of tooth enamel, and the soft drink caused the greatest reduction in microhardness. Among the beverages analysed the low calorie soft drink lemon soda and black tea ready to drink worsened the erosion in dental enamel.

KEY WORDS: Dental enamel. Tooth erosion. Hydrochloric acid. In Vitro 


\section{SUMÁRIO}

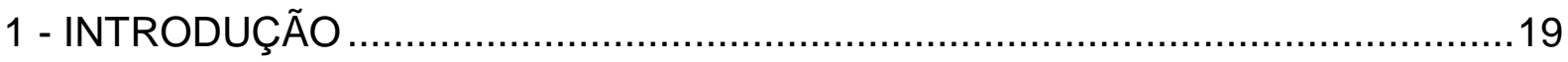

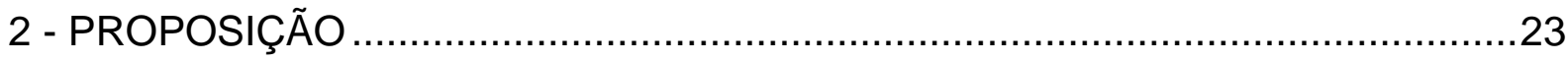

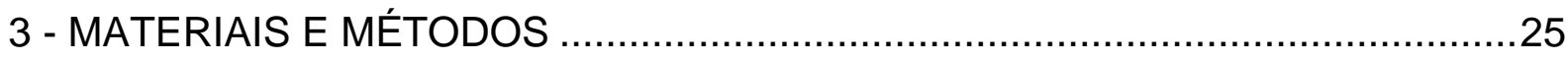

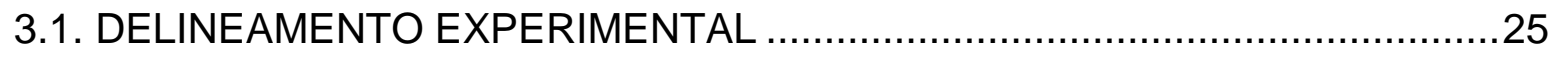

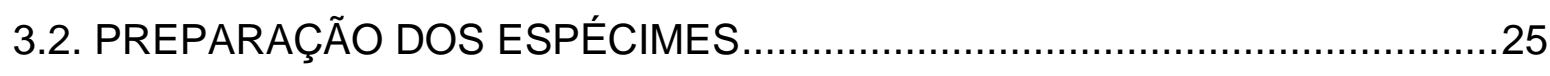

3.3. AVALIAÇÃO INICIAL DA MICRODUREZA E SELEÇÃO DOS ESPÉCIMES. 26

3.4. FORMAÇÃO DAS LESÕES DE DESGASTE EROSIVO …...........................26

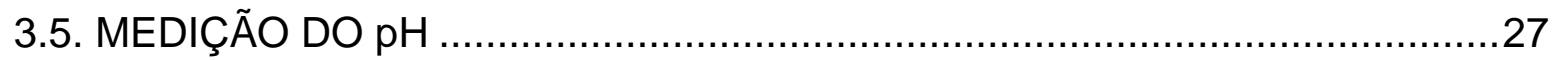

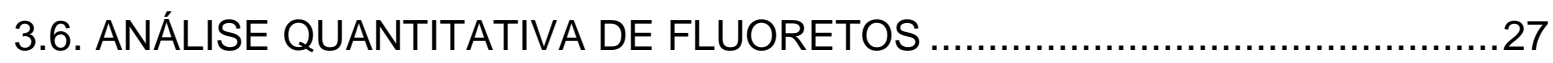

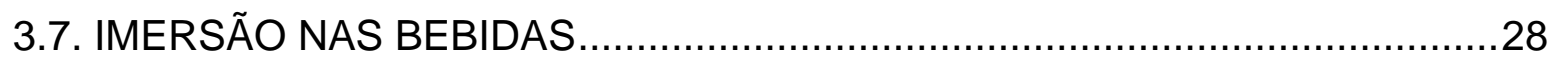

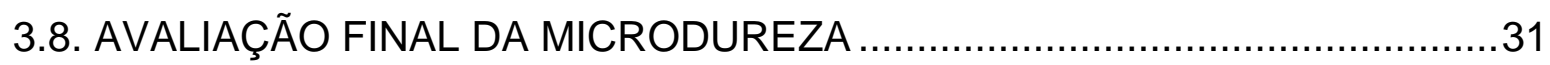

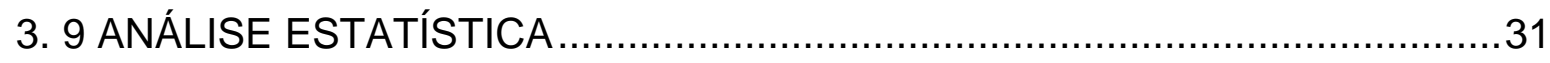

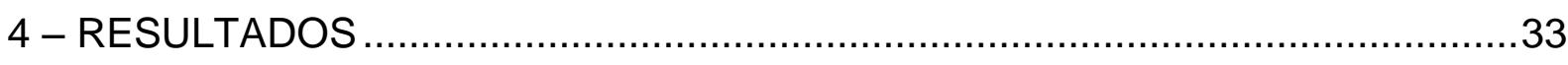

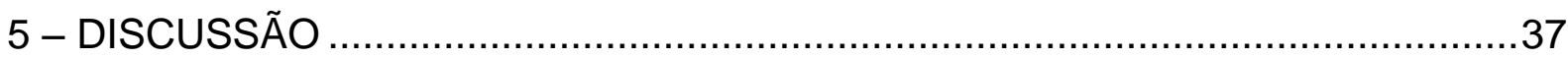

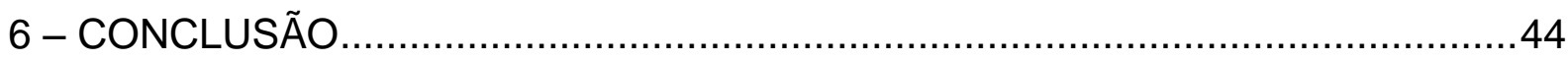

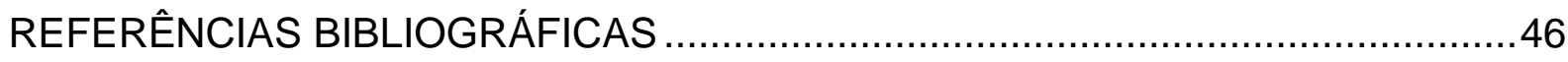


INTRODUÇÃO 


\section{1 - INTRODUÇÃO}

O desgaste dentário, incluindo a erosão dental, não é um fenômeno novo (LUSSI; JAEGGI; SCHAFFNER, 2002; MILOSEVIC, 2004), contudo é um problema crescente (BARTLETT, 2010). Acredita-se que a erosão é a causa predominante do desgaste dental em crianças e adultos jovens (CURZON; HEFFERREN, 2001). A incidência e a severidade das lesões aumentam com a idade (BARTLETT, 2010), embora dependam da sociedade onde o indivíduo está inserido (LUSSI; JAEGGI; SCHAFFNER, 2002).

A erosão dentária ou desgaste dentário erosivo é uma condição multifatorial (IMFELD, 1996; LUSSI; JAEGGI, 2008), caracterizada pela perda de tecido duro, através de corrosão química e dissolução por ácidos de origem não bacteriana (AMAECHI; HIGHAM, 2005), frequentemente intensificada por forças abrasivas intraorais (HARA; et al., 2003). Estes ácidos podem ter origem extrínseca (alimentares e ambientais) ou intrínseca os ácidos gastrointestinais (LUSSI; JAEGGI; SCHAFFNER, 2002).

Na clinica odontológica, as lesões de erosão dentária são um achado comum nos pacientes que apresentam regurgitação (IMFELD, 1996), como na doença do refluxo gastroesofágico (SCHROEDER et al., 1995; BARTLETT, 2006), ou episódios de vômitos recorrentes, como na anorexia e bulimia nervosa (BARTLETT, 2006). A presença constante de ácido gástrico na cavidade bucal tem sido associada ao desenvolvimento de severa erosão dentária (BARTLETT, 2006). Entretanto, inicialmente ocorreria a dissolução dos prismas da camada superficial do esmalte pelos componentes do ácido (LUSSI, 2008).

A frequência do consumo de bebidas ácidas também é fator de risco para lesão de erosão (ZERO, 1996; LUSSI et al., 2000, LUSSI; JAGGI; ZERO, 2004, BARTLETT, 2009), em dentes decíduos e permanentes (LUSSI et al., 2000). Sucos ácidos (LUSSI et al, 2000, AMAECHI; HIGHAM, 2005), como o de laranja (WEST et al., 1998), refrigerantes e bebidas carbonatadas (LUSSI; JAEGGI; ZERO, 2004) demonstraram efeito erosivo. A composição química de uma bebida estaria 
relacionada à erosão dentária (MEURMAN; FRANK, 1991) e a presença do ácido cítrico, um forte quelante de minerais dos tecidos dentários, tem sido associada à ação erosiva da bebida (LUSSI, JAEGGI, ZERO, 2004; YOUNG, 2005).

Por outro lado, a quantidade de cálcio, fosfato e flúor em uma bebida parece ser fator importante em relação ao potencial erosivo (LUSSI, JAEGGI, ZERO, 2004). Bebidas enriquecidas com cálcio apresentariam redução no potencial erosivo (LUSSI, 2009) e aumento na capacidade de remineralização (HARA; ZERO, 2008). Contudo, a adição de variadas e diferentes concentrações de sais de cálcio poderiam não só modificar o potencial erosivo, mas também alterar características originais das bebidas como sabor e cor (HARA; ZERO, 2008; LUSSI, 2009). Então, incentivar o consumo de leite ou outras bebidas como fontes naturais de cálcio poderia ser uma medida preventiva mais eficaz e menos dispendiosa que a suplementação de bebidas com este mineral.

O cálcio é essencial na estrutura de ossos e dentes (PATHOMRUNGSIYOUNGGUL; GRANDISON; LEWIS, 2007) e sua presença na composição do leite bovino, além de fosfoproteínas, poderia prevenir a dissolução do esmalte dental (DUARTE; COPPI; ROSALEN, 2000). A utilização do leite bovino foi recomendada em seqüência a um desafio erosivo para auxiliar na remineralização do esmalte dental erodido (GEDALIA et al., 1991; AMAECHI; HIGHAM, 2005). Alguns refrigerantes tiveram sua capacidade erosiva reduzida quando foram misturados com leite UHT (SYED; CHADWICK, 2009).

O extrato de soja, conhecido como "leite" de soja (ABREU et al., 2007, PATHOMRUNGSIYOUNGGUL; GRANDISON; LEWIS, 2007), também apresenta cálcio (ABREU et al., 2007) e proteínas (JESUDASON; CLIFTON, 2010) em sua composição. Produtos derivados da soja têm despertado interesse, devido aos benefícios à saúde atribuídos ao consumo desta leguminosa (BADGER et al., 2002; HEBER, 2004) e em decorrência da crescente hipersensibilidade ao leite bovino nas crianças em idade escolar e adultos jovens (PAAJANEN et al, 2005)

O chá preto, obtido através da fermentação das folhas da planta Camellia sinensis (MALINOWSKA et al., 2008), é uma bebida tradicional originária da China cujo consumo tem aumentado em escala mundial, através da industrialização de 
seus produtos (HAYACIBARA et al., 2004). Como o chá preto contém flúor (SIMPSON; SHAW; SMITH, 2001b, BEHRENDT; OBERSTE; WETZEL, 2002, MALINOWSKA et al., 2008), seu consumo poderia ter efeitos benéficos para o esmalte dentário, aumentando a resistência à dissolução ácida (SIMPSON; SHAW; SMITH, 2001a; BRUNTON; HUSSAIN, 2001). Contudo, a ingestão de bebidas a base de chá do tipo Ice tea poderia predispor a risco de erosão (BEHRENDT; OBERSTE; WETZEL, 2002), pela presença de outros ingredientes além do extrato de Camellia sinesis em sua composição.

Indivíduos com histórico de patologias que envolvam regurgitação ou vômito poderiam apresentar maior grau de desmineralização do esmalte dental, dependendo do tipo de bebida que habitualmente consumam. A erosão poderia ser mais evidente em decorrência da exposição simultânea do ambiente bucal a constantes desafios ácidos intrínsecos e extrínsecos.

Com intuito de prevenir e/ou controlar alterações minerais na superfície da estrutura dentária, seria relevante avaliar o efeito de bebidas frequentemente ingeridas, em espécimes de esmalte dentários, previamente erodidos com ácido clorídrico, empregando modelo experimental laboratorial. 


\section{2 - PROPOSIÇÃO}

O presente estudo tem por objetivo avaliar, através de um modelo experimental in vitro, o efeito das bebidas na microdureza superficial do esmalte dentário submetido a desafio erosivo com ácido clorídrico. 
MATERIAIS E MÉTODOS 


\section{3 - MATERIAIS E MÉTODOS}

\subsection{DELINEAMENTO EXPERIMENTAL}

O fator em estudo foi o tipo de bebida, em cinco níveis: refrigerante de limão de baixa caloria (controle positivo), leite integral UHT, extrato de soja integral, chá preto de baixa caloria pronto para beber e água mineral natural (controle negativo). A amostra do experimento foi composta por 75 espécimes de esmalte bovino, distribuídos entre os cinco tipos de bebida $(n=15)$, de acordo com delineamento em blocos completos e casualizados. A variável de resposta quantitativa foi a microdureza superficial (KHN) do esmalte.

\subsection{PREPARAÇÃO DOS ESPÉCIMES}

Da porção coronária de cinqüenta incisivos bovinos recém extraídos, previamente limpos e armazenados em solução de timol a $0,1 \%$ a $4^{\circ} \mathrm{C}$, foram obtidos cem espécimes de esmalte, medindo $5 \times 4 \mathrm{~mm}$, em cortadeira de precisão (Isomet 1000, Buehler, EUA). Os espécimes sem trincas foram fixados individualmente, com a superfície vestibular do esmalte voltada para cima, planificados e polidos em politriz giratória refrigerada a água (Beta Grinder-Polisher, Buehler Ltd., EUA), com lixas abrasivas de óxido de alumínio nas granulações 600 e 1200 (Norton, Brasil) e suspensão de alumina 0,3 $\mu \mathrm{m}$ (Buehler EUA). Para remover os resíduos do polimento, os corpos-de-prova foram levados ao Ultrassom Cleaner (Odontobrás, Brasil) por 10 minutos em água deionizada, até o momento da imersão em saliva artificial. 


\subsection{AVALIAÇÃO INICIAL DA MICRODUREZA E SELEÇÃO DOS ESPÉCIMES}

Cada um dos cem corpos-de-prova foi imerso em $20 \mathrm{ml}$ de saliva artificial (AMAECHI; HIGHAM; EDGAR, 1999), durante 48 horas, em temperatura de $37^{\circ} \mathrm{C}$. Posteriormente foram realizadas no microdurômetro HMV-2 (Shimadzu Corp, Japão) três indentações utilizando penetrador Knoop com carga estática de 25 gramas e tempo de aplicação de 30 segundos a partir da borda superior, separadas entre si por uma distância de $500 \mu \mathrm{m}$. Após as mensurações, foram selecionados 75 corpos de prova, cujos valores de microdureza de superfície encontravam-se mais próximos da média geral.

\subsection{FORMAÇÃO DAS LESÕES DE DESGASTE EROSIVO}

Os 75 espécimes selecionados tiveram a superfície vestibular isolada exceto uma área circular central de aproximadamente $5 \mathrm{~mm}^{2}$, antes da imersão individual em $10 \mathrm{ml}$ de solução aquosa de ácido clorídrico 0,01 M (HOVE et al., 2006), por 2 minutos. Após o desafio erosivo foram lavados com água deionizada e imersos em saliva artificial (AMAECHI; HIGHAM; EDGAR, 1999), durante 2 horas em temperatura de $37^{\circ} \mathrm{C}$. Decorrido este tempo, os corpos-de-prova foram retirados da saliva artificial, lavados em água deionizada e mantidos em umidade relativa até a leitura da microdureza superficial do esmalte (microdureza Knoop) realizada de forma semelhante à descrita para leitura inicial. 


\subsection{MEDIÇÃO DO pH}

$\mathrm{O} \mathrm{pH}$ das bebidas foi medido no pHmetro de bancada modelo mPA 210 ( MS Tecnopon Piracicaba-SP, Brasil) conectado a um eletrodo. Antes da mensuração o eletrodo foi calibrado utilizando soluções padrão de pH 4,0 e 7,0 respectivamente.

\subsection{ANÁLISE QUANTITATIVA DE FLUORETOS}

A determinação de fluoretos nas amostras foi realizada no laboratório de Bioquímica da Faculdade de Ciências Farmacêuticas de Ribeirão Preto-USP, utilizando o eletrodo seletivo combinado (Orion modelo 96-09) com ajuste de força iônica e $\mathrm{pH}$,utilizando tampão citrato $0,5 \mathrm{~mol} \mathrm{~L}^{-1}$, com pH 5,50 na proporção de 1:1 amostra/tampão. A concentração $(\mathrm{x}$ ) foi determinada pelo valor do respectivo potencial obtido $(\mathrm{y})$ e empregado a equação da reta $\mathbf{y}=\mathbf{a}+\mathbf{b} \log \mathbf{x}$, obtida por regressão linear de leituras em triplicatas de soluções padrões de fluoreto, diluídas convenientemente, onde a é o coeficiente linear da reta (slope) e b o coeficiente angular. A curva de calibração foi obtida a partir da leitura em $\mathrm{mV}$ das soluções padrões de fluoreto de sódio, em temperatura constante de $25^{\circ} \mathrm{C}$. As concentrações de fluoreto de sódio variaram de 0,2 a $1000 \mathrm{mg}^{-L^{-1}}$ (ppmF-). 


\subsection{IMERSÃO NAS BEBIDAS}

Os 75 espécimes previamente erodidos foram aleatoriamente divididos em cinco grupos e submetidos à imersão nas bebidas (três tratamentos experimentais e dois tratamentos controle), duas vezes ao dia por 2 dias, em temperatura ambiente. As imersões foram feitas sob agitação constante, na mesa agitadora orbital (CT155, Cientec, Piracicaba, SP, Brasil), com velocidade de 50 rpm durante 1 minuto, em recipientes do tipo becker contendo $20 \mathrm{ml}$ de cada uma das bebidas: Refrigerante de limão de baixa caloria Sprite Zero (Companhia de Bebidas Ipiranga, Ribeirão Preto, SP, Brasil), controle positivo; Leite UHT integral Parmalat (Companhia de alimentos Glória, Votuporanga, SP, Brasil); Extrato de soja integral Ades Original (Unilever Brasil alimentos Ltda, Pouso Alegre, MG, Brasil); Chá preto de baixa caloria pronto para beber Leão Ice Tea Zero sabor pêssego (Companhia de bebidas IpirangaRibeirão Preto, SP, Brasil) e Água mineral Prata (Concessionária: Águas da Prata Ltda, Águas da Prata, SP, Brasil), controle negativo. Nos intervalos entre as imersões nas bebidas durante 2 horas e até a imersão no dia seguinte por um período de18 horas, os corpos de prova permaneceram imersos individualmente em $20 \mathrm{ml}$ de saliva artificial (AMAECHI; HIGHAM; EDGAR, 1999), a 37ㄷ. 


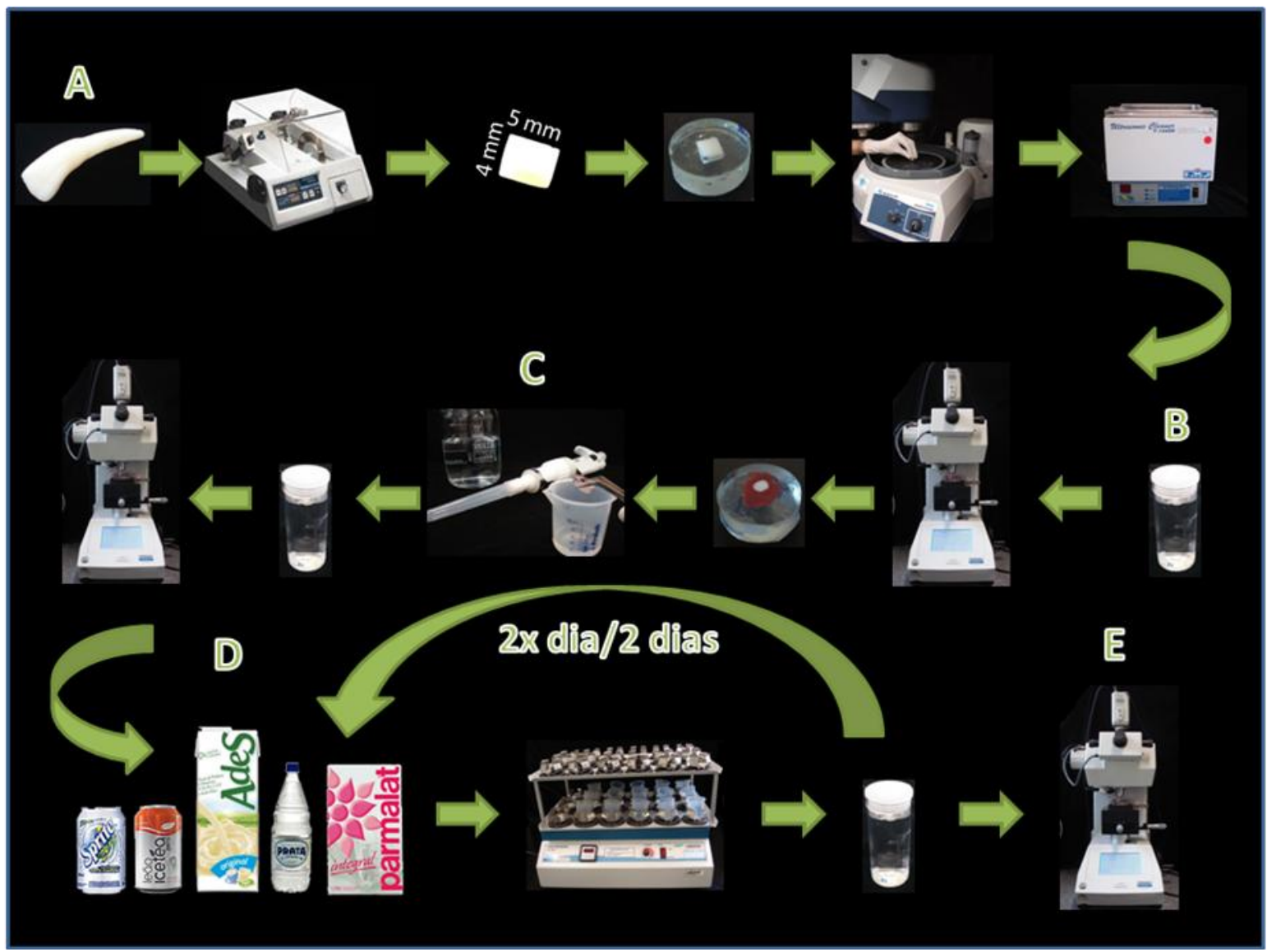

FIGURA 1: Fluxograma do experimento: A) Da porção coronária de cinquenta incisivos bovinos foram obtidos em cortadeira de precisão cem espécimes de esmalte medindo $5 \times 4 \mathrm{~mm}$. Depois de fixados os corpos de prova foram polidos na politriz e levados ao ultrassom, após o que foram imersos em saliva artificial por 48 horas. B) Em seguida foi feita mensuração da microdureza Knoop (KHN 1) para seleção de 75 espécimes. C) Foi feito desafio erosivo com $10 \mathrm{ml}$ de solução de $\mathrm{HCl} 1 \mathrm{M}$ durante 2 minutos. Posteriormente os corpos de prova ficaram imersos em $20 \mathrm{ml}$ de saliva artificial por 2 horas. Após o que foi realizada mensuração da microdureza (KHN 2). D) Imediatamente após teve inicio a imersão nas bebidas: duas vezes ao dia por 2 dias em $20 \mathrm{ml}$ por 1 minuto. sob agitação constante. Nos intervalos das imersões os corpos de prova permaneceram em saliva artificial. E) Após as imersões nas bebidas e saliva foi realizada a mensuração final de microdureza (KHN 3). 
TABELA 1 - Composição, pH e concentração de fluoretos das bebidas,.

\begin{tabular}{|c|c|c|c|}
\hline BEBIDAS & COMPOSIÇÃO* & $\mathrm{pH}^{\star \star}$ & $\begin{array}{l}\text { CONCENTRAÇÃO } \\
\text { DE FLUORETOS } \\
\mathrm{mg}^{* * L^{-1}}\end{array}$ \\
\hline $\begin{array}{l}\text { REFRIGERANTE DE } \\
\text { LIMÃO DE BAIXA } \\
\text { CALORIA } \\
\text { SPRITE® ZERO }\end{array}$ & $\begin{array}{ll}\text { - } & \text { Água gaseificada } \\
\text { - } & \text { Suco de limão } 2,5 \% \\
\text { - } & \text { Acidulante (ácido cítrico) } \\
\text { - } & \text { Aroma sintético idêntico ao } \\
& \text { natural } \\
\text { - } & \text { Edulcorantes artificiais } \\
\text { (ciclamato de sódio e sacarina } \\
\text { sódica) }\end{array}$ & 2,91 & $<0,2$ \\
\hline $\begin{array}{l}\text { CHÁ PRONTO PARA } \\
\text { BEBER DE BAIXA } \\
\text { CALORIA LEÃO® } \\
\text { ICE TEA ZERO }\end{array}$ & $\begin{array}{l}\text { - Água } \\
\text { - } \\
\text { - } \\
\text { Acidulatantes (ácido cítrico e } \\
\text { fosfórico) } \\
\text { - Aroma sintético idêntico ao } \\
\text { natural } \\
\text { - Conservadores (benzoato de } \\
\text { sódio e sorbato de potássio) } \\
\text { - Edulcorantes artificiais } \\
\text { (ciclamato de sódio e sacarina } \\
\text { de sódio) } \\
\text { - Sequestrante (hexametafosfato } \\
\text { de sódio) } \\
\text { - Antiespumante (dimetil } \\
\text { polisiloxano) }\end{array}$ & 3,02 & 0,760 \\
\hline ADES ${ }^{\circledR}$ ORIGINAL & 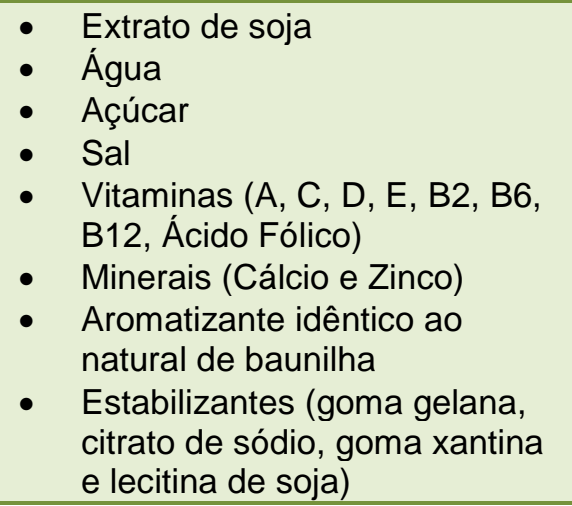 & 7,35 & 0,265 \\
\hline $\begin{array}{l}\text { ÁGUA MINERAL } \\
\text { NATURAL PRATA® }\end{array}$ & $\begin{array}{l}\text { Água mineral fluoretada } \\
\text { radioativa na fonte } \\
\text { Bicarbonato, sulfato, fluoreto, } \\
\text { sódio, potássio, magnésio, } \\
\text { cálcio, cloreto, nitrato }\end{array}$ & 6,29 & 0,220 \\
\hline $\begin{array}{l}\text { LEITE UHT INTEGRAL } \\
\text { PARMALAT }{ }^{\circledR}\end{array}$ & $\begin{array}{l}\text { - Leite padronizado com } 3 \% \text { de } \\
\text { gordura } \\
\text { - Estabilizantes (citrato de sódio, } \\
\text { trifosfato de sódio, monofosfato } \\
\text { de sódio e difosfato dissódico) }\end{array}$ & 6,63 & $<0,2$ \\
\hline
\end{tabular}

* Composição compilada a partir de dados fornecidos pelos fabricantes nas embalagens dos produtos.

** Valores de $\mathrm{pH}$ medidos no pHmetro.

*** Concentração de fluoretos nas amostras analisadas. Valores $<0,2$ estão abaixo da sensibilidade do eletrodo. 


\subsection{AVALIAÇÃO FINAL DA MICRODUREZA}

A microdureza final dos espécimes foi mensurada no microdurômetro HMV-2 (Shimadzu Corp, Japão), depois de concluída a imersão nas bebidas com igual carga e distância utilizadas anteriormente para a medida inicial e após imersão no ácido clorídrico, porém as indentações foram realizadas em área diferente das medidas anteriores

\subsection{ANÁLISE ESTATÍSTICA}

A homogeneidade de variância nas medidas de microdureza iniciais (KHN inicial) e após desafio com ácido clorídrico ( $\mathrm{KHN}$ após $\mathrm{HCl}$ ) foi verificada com o teste de Bartlett. Os dados originais de microdureza iniciais (KHN Inicial) e após desafio com ácido clorídrico (KHN após $\mathrm{HCl}$ ) foram submetidos à Análise de Variância com um fator (ANOVA Oneway), considerando o delineamento em blocos completos casualizados.

Para avaliar o efeito das bebidas no esmalte previamente erodido, foi considerada como variável de resposta a diferença entre as medidas de microdureza observadas após a imersão nas bebidas e as medidas observadas após o desafio com ácido clorídrico.

O teste de Tukey comparou o efeito das bebidas (MONTGOMERY, 1993). Os softwares STATA e $R$ foram utilizados para os cálculos estatísticos deste estudo. 


\section{4 - RESULTADOS}

O teste de Bartlett evidenciou homogeneidade de variância nas medidas de microdureza dos espécimes de esmalte dental inicial (KHN inicial) e após desafio com ácido clorídrico ( $\mathrm{KHN}$ após $\mathrm{HCl}$ ).

A ANOVA demonstrou que não houve diferenças significativas na microdureza dos espécimes de esmalte dental divididos entre os cinco grupos experimentais no inicio do experimento $-\mathrm{KHN}$ inicial - $(\mathrm{p}=0,8403)$. Também não houve diferenças significativas entre os valores de microdureza dos cinco grupos experimentais após o desafio com ácido clorídrico - medidas $\mathrm{KHN}$ após $\mathrm{HCl}$ $(p=0,8761)$.

A ANOVA demonstrou que as diferenças entre as medidas de microdureza do esmalte exposto ao ácido clorídrico e as bebidas testadas foram altamente significativas $(p<0.00001)$. O teste de Tukey identificou estas diferenças. $O$ refrigerante de limão provocou a maior diminuição da microdureza do esmalte, significativamente maior do que as demais bebidas testadas. A exposição do esmalte ao chá preto de baixa caloria provocou diminuição da microdureza superficial, significativamente maior do que a exposição à água mineral, ao extrato de soja e ao leite UHT integral, porém menor do que a provocada pelo refrigerante de limão. Não houve diferença entre leite UHT integral, extrato de soja e água mineral, que não proporcionaram diminuição adicional da microdureza superficial do esmalte previamente erodido com ácido clorídrico. 
TABELA 3 - Análise estatística das Medidas de dureza -KHN, desvio-padrão e Média das diferenças

\begin{tabular}{|c|c|c|c|c|}
\hline & $\begin{array}{c}\text { KHN-1 } \\
\text { KHN inicial }\end{array}$ & $\begin{array}{c}\text { KHN-2** } \\
\text { KHN originais } \\
\text { Pós HCl }\end{array}$ & $\begin{array}{c}\text { KHN-3 } \\
\text { KHN originais } \\
\text { Pós Bebidas }\end{array}$ & $\begin{array}{l}\text { Média das } \\
\text { Diferenças ** }\end{array}$ \\
\hline Refrigerante de limão & $361,42( \pm 29,97)$ a & $227,38( \pm 37,27)$ a & $97,52( \pm 16,75)$ & $-129,86( \pm 38,64) \mathrm{a}$ \\
\hline Extrato de soja & $361,98( \pm 37,52) a$ & $221,80( \pm 35,86) \mathrm{a}$ & $235,07( \pm 43,99)$ & $+13,27( \pm 44,59) \mathrm{C}$ \\
\hline Água mineral & $354,39( \pm 33,09)$ a & $231,47( \pm 45,86) a$ & $246,94( \pm 31,85)$ & $+15,47( \pm 33,14) \mathrm{c}$ \\
\hline
\end{tabular}




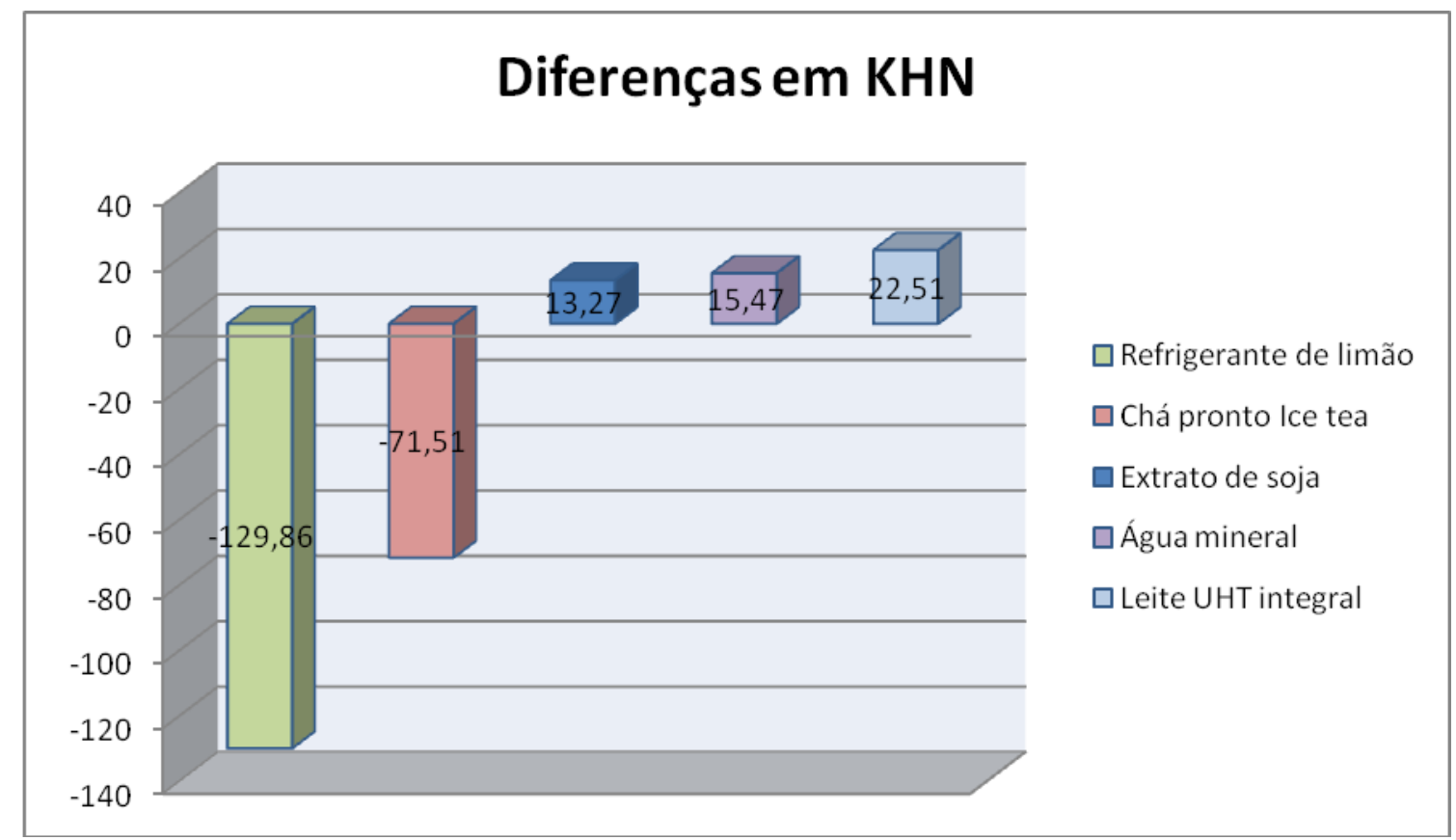

GRÁFICO 1: Diferenças entre as médias de microdureza superficial do esmalte após o desafio com ácido clorídrico e imersões nas bebidas. 


\section{5 - DISCUSSÃO}

A erosão dental é frequentemente observada em indivíduos que apresentam transtornos alimentares com vômitos autoinduzidos (BARTLETT, 2006), e também nos que apresentam doença do refluxo gastroesofágico (SCHROEDER et al., 1995; BARTLETT 2006; HOVE et al., 2006). Nestas situações, o teor de ácido gástrico proveniente do estômago pode afetar a estrutura dental (HARA, PURQUERIO; SERRA, 2005, HOVE et al., 2006), em decorrência do contato frequente com o fluido ácido (AMORAS et al, 2010), composto principalmente por ácido clorídrico (BARTLETT, 2006).

O protocolo utilizado para a formação das lesões de erosão foi adaptado do modelo in vitro de MESSIAS; SERRA; TUSSI, 2008. Com intuito de simular o contato da superfície dental com conteúdo gástrico, decorrente de episódios de refluxo ou vômito, e tornar a simulação clinicamente mais relevante, foi utilizado o ácido clorídrico 0,01 M (HOVE et al., 2006) ao invés de suco de laranja. Como o ácido clorídrico é um ácido forte (WEST; HUGHES; ADDY, 2001), o desafio erosivo foi ajustado para uma única imersão, em menor tempo (2 minutos ao invés de 5 minutos) e menor volume de solução ácida ( $10 \mathrm{ml}$ ao invés de $20 \mathrm{ml}$ ).

Os resultados obtidos após o desafio com ácido clorídrico indicam a padronização uniforme da imersão. Assim como, os resultados obtidos por meio das medidas de KHN iniciais sugerem que os espécimes de esmalte bovino foram selecionados, padronizados e aleatorizados adequadamente, visto que não houve diferenças significativas na dureza superficial do esmalte nos grupos experimentais. O desafio ácido foi conduzido de maneira apropriada e houve diminuição na dureza superficial do esmalte em todos os espécimes.

Neste experimento foram utilizadas cinco bebidas comercialmente disponíveis. O refrigerante à base de limão foi selecionado como controle positivo por conta do seu reconhecido potencial erosivo (LUSSI et al., 2000, LUSSI; JAEGGI; ZERO, 2004). A opção de testar o leite bovino teve relação com a presença de 
cálcio e caseína uma importante fosfoproteína (GEDALIA et al., 1991; MCDOUGALL, 1997; DUARTE; COPPI; ROSALEN, 2000) que poderiam inibir a desmineralização ativando a remineralização. O extrato de soja integral foi incluído no experimento por também apresentar cálcio e proteínas em sua composição (ABREU et al., 2007, JESUDASON; CLIFTON, 2010). A escolha da água mineral como controle negativo está relacionada à ausência de substâncias erosivas em sua composição, e também, por ser preconizada como uma bebida segura frente aos problemas causados pelos refrigerantes em relação à erosão dentária (PARRY et al., 2001). A inclusão do chá preto está relacionada à presença de flúor em sua composição (HAYACIBARA et al., 2004, MALINOWSKA et al., 2008). A forma de apresentação do chá na versão pronta para beber com baixa caloria foi escolhida em virtude da praticidade e aceitação por indivíduos que querem manter a saúde e não aumentar o peso corporal.

A imersão em $20 \mathrm{ml}$ em cada uma das bebidas duas vezes ao dia por 2 dias foi igual ao proposto por MESSIAS; SERRA; TUSSI, 2008 o tempo de 60 segundos foi escolha dos autores por melhor se adaptar ao delineamento do experimento.

Analisando os resultados do presente estudo, verifica-se que o refrigerante de limão com baixa caloria proporcionou diminuição na microdureza superficial, significativamente maior do que as demais bebidas. Uma provável justificativa para este fato poderia ser a presença do ácido cítrico e suco de limão na composição do refrigerante utilizado. A composição química de uma bebida ácida é importante no que diz respeito à erosão dentária (MEURMAN; FRANK, 1991). O ácido cítrico é adicionado para acentuar o sabor de limão, contudo é um forte quelante de minerais, responsável pela corrosão dental (YOUNG, 2005). A erosão ocorre porque o conteúdo mineral do esmalte é solúvel em ambiente ácido (MILOSEVIC, 2004). O potencial erosivo de uma bebida tem relação entre outros fatores, com a acidez total e com o tipo de ácido que a constitui. Os resultados obtidos neste experimento corroboram com outros estudos in vitro quanto ao potencial erosivo de refrigerantes (JÄRVINEN; RYTÖMAA; HEINONEN, 1991; GEDALIA et al., 1991; LUSSI et al., 2000).

O chá preto de baixa caloria pronto para beber utilizado neste estudo provocou diminuição da microdureza superficial significativamente diferente que a 
água mineral, o extrato de soja e o leite UHT integral, porém menor que a provocada pelo refrigerante à base de limão. A presença de acidulantes (ácido cítrico e fosfórico), no chá preto testado pode ter contribuído para este resultado. Estes ácidos são os dois principais ácidos alimentares presentes nos refrigerantes (WEST; HUGHES; ADDY, 2001). A praticidade do Ice tea poderia facilitar seu consumo, contudo apresenta potencial erosivo anteriormente evidenciado por BEHRENDT; OBERSTE; WETZEL (2002). A presença de flúor na composição do chá preto testado, não foi declarada pelo fabricante na embalagem do produto, mas foi evidenciada através de análise quantitativa com resultado de 0,760 $\pm 0,049$. O flúor presente no chá analisado não foi capaz de impedir a desmineralição do esmalte, contrariando a expectativa, uma vez que, a inclusão desta bebida foi em função da presença deste mineral. O flúor não proporcionaria efeito protetor no esmalte quando presente em bebidas carbonatadas ácidas (LARSEN; RICHARDS, 2002). SIMPSON; SHAW; SMITH, (2001b) concluíram que o chá preto em função da presença de flúor seria indicado como substituto de bebidas ácidas da dieta. Contudo, BEHRENDT; OBERSTE; WETZEL (2002) avaliaram 44 amostras de chá, sendo 28 de chá preto e concluíram que os produtos "Ice tea" apresentariam potencial erosivo. Possivelmente, os efeitos benéficos do flúor contido no chá preto sejam mais bem aproveitados quando a forma de consumo escolhida for a mais tradicional embora menos prática, ou seja, infusão.

Neste estudo, o leite UHT integral, o extrato de soja e a água mineral não proporcionaram diminuição adicional na microdureza superficial do esmalte. O leite e sua relação com a estrutura dental tem sido um tópico de bastante interesse, em decorrência do seu amplo consumo (DUARTE; COPPI; ROSALEN, 2000). O conteúdo de cálcio e outros minerais presentes no leite colaborariam na remineralização do esmalte (GEDALIA et al., 1991; DUARTE; COPPI; ROSALEN, 2000). A identificação dos agentes protetores presentes no leite, tem progredido, contudo o esclarecimento completo do seu papel na proteção contra o ataque ácido sobre o esmalte dentário seria dificultado devido sua natureza complexa (GRENBY et al., 2001). Verificou-se que o leite não apresentou o efeito remineralizante esperado, uma provável interpretação deste resultado estaria relacionada ao tempo total de exposição ao leite (4 minutos), e ao modelo (estudo in vitro). No meio bucal 
(in vivo) poderia ocorrer uma maior aderência à superfície dental, potencializando o efeito remineralizante do leite.

$\mathrm{O} \mathrm{pH}$ e a titulação ácida do suco gástrico apresentam-se maiores que os dos ácidos alimentares de origem extrínseca, favorecendo um maior nível de destruição dos tecidos dentais (BARTLETT; COWARD, 2001). Esta poderia ser uma possível explicação para o fato de bebidas como o leite UHT e o extrato de soja não terem atenuado o processo de desmineralização do esmalte previamente erodido com ácido clorídrico. O polimento da superfície dos espécimes poderia ser outra questão interessante, pois inevitavelmente remove a camada superficial externa do esmalte (MEURMAN; FRANK, 1991).

A escolha do extrato de soja integral teve relação com seu elevado consumo por indivíduos que apresentam intolerância a proteína do leite, preocupados em consumir alimentos saudáveis ou aqueles interessados nos efeitos positivos da soja. A literatura cientifica aponta benefícios à saúde referentes ao consumo de produtos derivados desta leguminosa (BADGER et al., 2002; HEBER, 2004; PATHOMRUNGSIYOUNGGUL; GRANDISON; LEWIS, 2007). A utilização de bebidas com cálcio como o "leite" de soja seria uma interessante medida preventiva. Contudo o extrato de soja apesar de não reduzir adicionalmente a microdureza superficial do esmalte não foi capaz de remineralizar o esmalte erodido pelo ácido clorídrico. Considerando a ausência de pesquisas sobre este tema, são necessários mais estudos para esclarecer o efeito do extrato de soja no esmalte dental.

A água mineral natural não apresentou redução adicional na microdureza superficial do esmalte, bem como, efeito remineralizante, sugerindo que embora a água apresentasse flúor na composição este não foi capaz de controlar a progressão da lesão de erosão. A ingestão de água é defendida como medida para um estilo de vida saudável. A falta de água em quantidade suficiente pode propiciar aumento na predisposição ao desgaste dental devido a diminuição na proteção salivar (YOUNG, 2005).

A saliva é um importante fator modulador da gravidade e progressão da erosão dentária (MESSIAS et al., 2010). Através da sua capacidade tampão, diluição dos ácidos, remineralização e formação da película adquirida (HARA; LUSSI; ZERO, 
2006). A saliva artificial (AMAECHI; HIGHAM; EDGAR, 1999) foi utilizada neste experimento para simular o ambiente bucal com intuito de compensar as limitações do modelo in vitro. Após a imersão nas bebidas não foi evidenciada remineralização da estrutura dental, o que demonstra a importância do conhecimento do potencial erosivo das bebidas comumente consumidas.

A microdureza superficial foi utilizada neste estudo como variável de resposta, por permitir avaliar as alterações superficiais nos tecidos dentais submetidos a desafios erosivos (BARBOUR; REES, 2004; ATTIN, 2006). O efeito do ácido clorídrico e das bebidas seria mais evidente nos estágios iniciais de dissolução do esmalte (BARBOUR; REES, 2004).

O elevado consumo de bebidas ácidas classificadas como agentes erosivos exógenos, têm crescente participação na etiologia das lesões de desgaste dental corrosivo. O diagnostico precoce das alterações dentais (SERRA; MESSIAS; TURSSI, 2009), a análise do tipo de bebida consumida (YOUNG, 2005), orientações referentes às atitudes preventivas (SERRA; MESSIAS; TURSSI, 2009) podem efetivamente influir na evolução da lesão de desgaste erosivo. A redução e/ou substituição de bebidas com potencial de desmineralizar o esmalte dentário, é um importante fator na prevenção de danos a estrutura dental, principalmente, em indivíduos com patologias que envolvam contato do ácido clorídrico com a cavidade bucal através da regurgitação e vômito.

Nas sociedades ocidentais modernas o fator extrínseco "dieta" é cada vez mais importante (LUSSI; JAEGGI; JAEGGI-SCHÄRER, 1995) devido ao elevado consumo de bebidas potencialmente erosivas. Reduzir o contato freqüente dos tecidos dentais com substâncias ácidas (SERRA; MESSIAS; TUSSI, 2009) é uma forma de prevenir e controlar (HOVE et al., 2006), os danos irreversíveis à estrutura dental

Em termos práticos, profissionais e pacientes devem estar cientes que bebidas ácidas e os ácidos gástricos como o ácido clorídrico, podem causar danos irreversíveis a estrutura dental (SERRA; MESSIAS; TURSSI, 2009). Para aqueles indivíduos com patologias em que o ácido é reconhecido fator de erosão dental, como transtornos alimentares do tipo anorexia e bulimia nervosa (BARTLETT, 2006; 
BARTLETT, 2009) e doença do refluxo gastroesofágico (LAZARCHICK; FRAZIER, 2009), o risco de desgaste dental erosivo é real sendo aconselhável reduzir a frequência da ingestão de bebidas potencialmente prejudiciais (SERRA; MESSIAS; TURSSI, 2009), pois a presença do desafio endógeno e exógeno simultaneamente poderia agravar e/ou acelerar o processo de desmineralização da superfície do esmalte dentário. Muitos pacientes com transtornos alimentares conseguem se recuperar por longos períodos ou mesmo de forma permanente, contudo a erosão dental é irreversível e medidas para controlar o processo erosivo devem ser iniciadas o mais cedo possível (HOVE et al., 2006). Neste sentido os dentistas desempenham um importante papel no tratamento global dos indivíduos com patologias que envolvem regurgitação do ácido gástrico para cavidade bucal, orientando quanto às bebidas que devem ser evitadas. Com intuito de prevenir danos (progressão e severidade) à estrutura dental, preservar a saúde e manter a qualidade de vida. 
CONCLUSÃO 
6 - CONCLUSÂO

Nas condições em que o estudo foi conduzido concluiu-se que:

- O refrigerante de limão com baixa caloria e o chá preto de baixa caloria potencializaram a erosão do esmalte dental, sendo que o refrigerante provocou a maior redução na microdureza superficial.

O leite UHT integral, o extrato de soja integral e água mineral natural, não proporcionaram diminuição adicional da microdureza superficial do esmalte previamente erodido com ácido clorídrico. 
REFEREANCIAS BIBLIOGRÁFICAS 


\section{REFERÊNCIAS BIBLIOGRÁFICAS ${ }^{\star * \star}$}

1. ABREU, C.R.A.; PINHEIRO, A.M.; MAIA, G.A.; CARVALHO, J.M.; SOUSA, P.H.M. Avaliação química e físico-quimica de bebidas de soja com frutas tropicais. Alimentos e Nutrição, Brazilian Journal of Food and Nutrition, v. 18, n. 3, p.291-296, 2007.

2. AIMUTIS, W.R. Bioactive properties of milk proteins with particular focus on anticariogenesis. The Journal of nutrition, v.134, n.4, p.989-995, 2004.

3. AMORAS, D.R.; MESSIAS, D.C.F.; RIBEIRO, R.P.P.; TURSSI, C.P.; SERRA, M.C. Caracterização dos transtornos alimentares e suas manifestações na cavidade bucal. Revista de Odontologia da UNESP, v.39, n.4, p.241-245, 2010. Disponível em: <http://rou.hostcentral.com.br/PDF/v39n4a09.pdf> Acesso em 15 out.2010.

4. ATTIN, T. Methods for assessment of dental erosion. Monographs in Oral Science, v.20, p.152-172, 2006.

5. AMAECHI, B.T.; HIGHAM, S.M.; EDGAR, W.M. Techniques for the production od dental eroded lesions in vitro. Journal of Oral Rehabilitation, v.26, n.2, p.97-102, 1999.

6. AMAECHI, B.T.; HIGHAM, S.M. Dental erosion: possible approaches to prevention and control. Journal of Dentistry, v.33, n.3, p.243-252, 2005.

7. BADGER, T.M; RONIS, M.J.J.; HAKKAK, R.; ROWLANDS, J.C.; KOROURIAN, S. The health consequences of early soy consumption. The Journal of Nutrition, v. 132, n.3, p.559S-565S, 2002.

8. BARBOUR, M.E.; REES, J.S. The laboratory assessment of enamel erosion: a review. Journal of Dentistry, v.32, n.8, p.591-602, 2004. 
9. BARTLETT, D.W.; COWARD, P.Y. Comparison of the erosive potential of gastric juice and a carbonated drink in vitro. Journal of Oral Rehabilitation, v.28, n11, p. 1045-1047, 2001.

10. BARTLETT, D. Intrinsic causes of erosion. Monographs in Oral Science, v.20, p.119-139, 2006.

11. BARTLETT, D. Etiology and prevention of acid erosion. Compendium of Continuing Education in Dentistry, v.30, n.9, p.616-620, 2009.

12. BARTLETT, D. A proposed system for screening tooth wear. British Dental Journal, v.208, n.5, p.207-209, 2010.

13. BEHRENDT, A.; OBERSTE, V.; WETZEL, W.E. Fluoride concentration and pH of iced tea products. Caries Research, v.36, n.6, p.405-410, 2002.

14. BOWEN, W.H.; PEARSON, S.K. Effect of milk on cariogenesis. Caries Research, v.27, n.6, p.461-466, 1993.

15. BRUNTON, P.A.; HUSSAIN, A. The erosive effect of herbal tea on dental enamel. Journal of Dentistry, v.29, n.8, p.517-520, 2001.

16. CURZON, M.E.J.; HEFFERREN J.J. Modern methods for assessing the cariogenic and erosive potential of foods. British Dental Journal, v.191, n.1, p.41-46, 2001.

17. DUARTE, P.M.; COPPI, L.C.; ROSALEN, P.L. Cariogenicity and cariostatic properties of different types of milk - review. Archivos Latinoamericanos de Nutrición, v.50, n.2, p.113-120, 2000.

18. GEDALIA, I.; DAKUAR, A.; SHAPIRA, L.; LEWINSTEIN, I.; GOULTSCHIN, J.; RAHAMIM, E. Enamel softening with Coca-Cola and rehardening with milk or saliva. American Journal of Dentistry, v.4, n.3, p.120-122, 1991.

19. GRENBY, T.H.; ANDREWS, A.T.; MISTRY, M.; WILLIAMS, R.J.H. Dental caries-protective agents in milk and milk products: investigations in vitro. Journal of Dentistry, v.29, n.2, p.83-92, 2001. 
20. HARA, A.T.; PURQUERIO, B.M.; SERRA, M.C. Estudo das lesões cervicais não-cariosas: aspectos biotribológicos. Revistada da Pós Graduação USP, v.12, n.11, p.141-148, 2005.

21. HARA, A.T.; TURSSI, C.P.; TEIXEIRA, E.C.; SERRA, M.C.; CURY, J.A. Abrasive wear on eroded root dentine after different periods of exposure to saliva in situ. European Journal of Oral Sciences, v.111, n.5, p.423-427, 2003.

22. HARA, A.T.; LUSSI, A; ZERO, D.T. Biological Factors. Monographs in Oral Science, v.20, p.88-99, 2006.

23. HARA, A.T.; ZERO, D.T. Analysis of the erosive potential of calciumcontaining acid beverages. European Journal of Oral Sciences, v.116, n.1, p.60-65, 2008.

24. HAYACIBARA, M. F.; QUEIROZ, C.S.; TABCHOURY, C.P.M.; CURY, J.M. Fluoride and aluminum in teas and tea-based beverages. Revista de Saúde Pública, v.38, n.1, p.100-105, 2004.

25. HEBER, D. Vegetables, fruits and phytoestrogens in the prevention of diseases. Journal of Postgraduate Medicine, v.50, n.2, p.145-149, 2004.

26. HOVE, L.; HOLME, B.; ØGAARD, B.; WILLUMSEN, T.; TVEIT, A.B. The protective effect of $\mathrm{TiF}_{4}, \mathrm{SNf}_{2}$, and $\mathrm{NaF}$ on erosion of enamel by hydrochloric acid in vitro measured by white light interferometry. Caries Research, v.40, n. 5, p.440-443, 2006.

27. IMFELD, T. Dental erosion, definition classification and links. European Journal of Oral Sciences, v.104, p.151-155, 1996.

28. JÄRVINEN, V.K.; RYTÖMAA, I. I.; HEINONEN, O.P. Risk factors in dental erosion. Journal of Dental Research, v.70, n.6, p.942-947, 1991.

29. JESUDASON, D.; CLIFTON, P. The interaction between dietary protein and bone health. Journal of bone and mineral metabolism, Epub ahead of print, 2010. 
30. LARSEN, M.J.; RICHARDS, A. Fluoride is unable to reduce dental erosion from soft drinks. Caries Research, v.36, n.1, p.75-80, 2002.

31. LAZARCHIK, D.A.; FRAZIER, K.B. Dental erosion and acid reflux disease: an overview. General Dentistry, v. 57, n.2, p.151-156, 2009.

32. LUSSI, A.; JAEGGI, T. JAEGGI-SCHÄRER, S. Prediction of the erosive potential of some beverages. Caries Research, v.29, p.349-354, 1995.

33. LUSSI, A.; KOHLER, N.; ZERO, D.; SCHAFFNER, M.; MEGERT, B. A comparison of the erosive potential of different beverages in primary and permanent teeth using an in vitro model. European Journal of Oral Sciences, v.108 n. 2, p.110-114, 2000.

34. LUSSI, A.; JAEGGI, T.; SCHAFFNER, M. Diet and dental erosion. Nutrition, v. 18, n.9, p.780-781, 2002.

35. LUSSI, A.; JAEGGI, T.; ZERO, D. The role of diet in the aetiology of dental erosion. Caries Research, v.38, suppl.1, p.34-44, 2004.

36. LUSSI, A.; JAEGGI, T.; Erosion - diagnosis and risk factors. Clinical Oral Investigations, v.12, p.S5-S13, 2008.

37. LUSSI, A. Dental erosion - Novel remineralizing agents in prevention or repair. Advances in Dental Research, v.21, n.1, p.13-16, 2009.

38. MALINOWSKA, E.; INKIELEWICZ, I.; CZARNOWSKI, W.; SZEFER, P. Assessment of fluoride concentration and daily intake by human from tea and herbal infusions. Food and chemical Toxology, v.46, n.3, p.1055-1051, 2008.

39. MCDOUGALL W.A. Effect of milk on enamel demineralization and remineralization in vitro. Caries Research, v.11, n.3, p.166-172, 1977.

40. MESSIAS, D.C.; MARTINS, M.E.; SERRA, M.C.; TURSSI, C.P. Feasibility of using sodium bicarbonate as a damage-limiting strategy for erosion lesions. Oral Health \& Preventive Dentistry, v. 6, n. 2, p. 155-158, 2008. 
41. MESSIAS, D.C.F.; TURSSI, C.P.; HARA, A.T.; SERRA, M.C. Sodium bicarbonate solution as an anti-erosive agent against simulated endogenous erosion. European Journal of Oral Sciences, v.118, p. 385-388, 2010.

42. MEURMAN, J.H.; FRANK, R.M. Progression and surface ultrastructure of in vitro caused erosive lesions in human and bovine enamel. Caries Research, v.25, n.2, p.81-87, 1991.

43. MILOSEVIC, A. Dietary acids - a risk to dental health? British Food Journal, v.106, n.6, p.457-464, 2004.

44. MONTGOMERY, D.C. Design and analysis of experiments. 3rd.ed. Arizona State University: J.Wiley, cap.4 p.102-103; cap.5 p.151-156, 2003.

45. MOYNIHAN, P.J. Dietary advice in dental practice. British Dental Journal, v.193, n.10, p.563-568, 2002.

46. PAAJANEN, L.; KORPELA, R.; TUURE, T.; HONKANEN, J.; JÄRVELÄ I.; ILONEN, J.; KNIP, M.; VAARALA, O.; KOKKONEN, J. Cow milk is not responsible for most gastrointestinal immune-like syndromes-evidence from a population-based study. The American Journal of Clinical Nutrition, v.82, n. 6, p.1327-1335, 2005.

47. PATHOMRUNGSIYOUNGGUL, P.; GRANDISON, A.S.; LEWIS, M.J. Effects of calcium chloride and sodium hexametaphosphate on certain chemical and physical properties of soymilk, Journal of Food Science. v.72, n.8, p.428434, 2007.

48. ROSA, S.E.S.; COSENZA, J.P.; LEÃO, L.T.S. Panorama do setor de bebidas no Brasil. BNDES setorial RJ, v.23, p.101-150, 2006.

49. SCHROEDER, P.L.; FILLER, S.J.; RAMIREZ, B.; LAZARCHICK, D.A.; VAEZI, M.F.; RICHTER, J.E. Dental erosion and acid reflux disease. Annais of International Medicine, v.122, n.11, p.809-815, 1995.

50. SERRA, M.C.; MESSIAS, D.C.F.; TURSSI, C.P. Control of erosive tooth wear: possibilities and rationale. Brazilian Oral Research, v.23, p.S49-S55, 2009 
51. SIMPSON, A.; SHAW, L.; SMITH, A.J. The bio-availability of fluoride from black tea. Journal of Dentistry, v.29, n.1, p.15-21, 2001a.

52. SIMPSON, A.; SHAW, L.; SMITH, A.J. Tooth surface $\mathrm{pH}$ during drinking of black tea. British Dental Journal, v.190, n.7, p.374-376, 2001b.

53. SYED, J.; CHADWICK, R.G. A laboratory investigation of consumer addition of UHT milk to lessen the erosive potential of fizzy drinks. British Dental Journal, v. 206, n. 3, p.154-161, 2009.

54. WEST, N.X.; MAXWELL, A.; HUGHES, A.; PARKER, D. M.; NEWCOMBE, R.G.; ADDY, M. A method to measure clinical erosion: the effect of orange juice consumption on erosion of enamel. Journal of Dentistry, v. 26, n.4, p.329-335, 1998.

55. WEST, N.X.; HUGHES, J. A.; ADDY, M. The effect of $\mathrm{pH}$ on the erosion of dentine and enamel by dietary acids in vitro. Journal of Oral Rehabilitation, v 28, p. 860-864, 2001.

56. YOUNG, W.G. Tooth wear: diet analysis and advice. International Dental Journal, v.55, n.2, p.68-72, 2005.

57. ZERO, D.T. Etiology of dental erosion-extrinsic factors. European Journal of Oral Sciences, v.104, n.2, p.162-177, 1996. 